\title{
pesquisa
}

SILVA, P.S.L.; SILVA, P.I.B. Parcelamento da adubação nitrogenada e rendimento de espigas verdes de milho. Horticultura Brasileira, Brasília, v. 21, n. 2, p. 149-152, abril/junho 2003 .

\section{Parcelamento da adubação nitrogenada e rendimento de espigas verdes de milho}

\author{
Paulo S. L. Silva; Paulo I. B. Silva \\ ESAM, C. Postal 137, 59625-900 Mossoró-RN. E-mail: paulosergio@esam.br
}

\section{RESUMO}

Avaliaram-se os efeitos da época da aplicação de nitrogênio (120 $\mathrm{kg} \mathrm{N} \mathrm{ha}^{-1}$, como sulfato de amônio) e do parcelamento dessa aplicação sobre o rendimento de espigas verdes de milho, em dois anos, em Mossoró, sob irrigação por aspersão. Avaliaram-se o número e peso total de espigas verdes empalhadas e o número e peso de espigas comercializáveis, empalhadas e despalhadas. Utilizou-se o delineamento de blocos ao acaso com quatro repetições. Os tratamentos aplicados foram: aplicação de todo o nitrogênio por ocasião do plantio (1-0-0) ou em cobertura aos 25 (0-1-0) ou aos 45 (0-0-1) dias após o plantio e aplicação do fertilizante de forma parcelada $(0-1 / 3-2 / 3,1 /$ $3-0-2 / 3,1 / 3-2 / 3-0,0-1 / 2-1 / 2,1 / 2-0-1 / 2,1 / 2-1 / 2-0,0-2 / 3-1 / 3,2 / 3-0-$ $1 / 3,2 / 3-1 / 3-0$ e $1 / 3-1 / 3-1 / 3)$. Os efeitos dos tratamentos foram independentes dos efeitos de anos. Os tratamentos $(0-0-1)$ e $(0-1 / 3-2 / 3)$ foram os que, em geral, proporcionaram os maiores rendimentos, mas outros tratamentos propiciaram rendimentos comparáveis, estatisticamente. Os piores rendimentos foram obtidos com o tratamento $1-0-0$.

Palavras-chave: Zea mays L., milho verde, época de aplicação de nitrogênio.

\begin{abstract}
Splitting of the nitrogen fertilization and green ears yield of maize

A 2-year study was conducted in Mossoró county, Brazil, under sprinkler irrigation conditions, to evaluate the effects of timing and split applications of nitrogen fertilizer $\left(120 \mathrm{~kg} \mathrm{~N} \mathrm{ha}^{-1}\right.$ as ammonium sulphate) on green ears yield of maize. The total number and weight of ears with husk and number and weight of marketable ears with and without husk were evaluated. A randomized block design with four replications was used. The applied treatments were: whole $\mathrm{N}$ application in preplanting (1-0-0) or side dressed at $25(0-1-0)$ or at $45(0-0-1)$ days after planting and split applications $(0-1 / 3-2 / 3,1 / 3-$ $0-2 / 3,1 / 3-2 / 3-0,0-1 / 2-1 / 2,1 / 2-0-1 / 2,1 / 2-1 / 2-0,0-2 / 3-1 / 3,2 / 3-0-1 /$ $3,2 / 3-1 / 3-0$ and $1 / 3-1 / 3-1 / 3$ ). The effects of the treatments were independent of the effects of years. The (0-0-1) and (0-1/3-2/3) treatments, in general, resulted in the highest yield, but other treatments also gave similar yields. The worse yield was obtained with 1-0-0 treatment.
\end{abstract}

Keywords: Zea mays L., green corn, timing of $\mathrm{N}$ application.

(Recebido para publicação em 16 de maio de 2001 e aceito em 25 de março de 2003)

$\mathrm{O}$ milho verde com teor de umidade entre $70 \%$ e $80 \%$, é produzido no estado do Rio Grande do Norte com irrigação e, especialmente, sob condições de seca. Com o apoio à irrigação concedido pelos governos estadual e federal, aumentou a área irrigada e o cultivo ocorre, atualmente, durante quase todo o ano. Mesmo as grandes empresas, que têm a fruticultura como principal atividade, têm usado o milho como cultura rotacional. $\mathrm{O}$ grande interesse por seu cultivo deve-se a que o produto é muito apreciado pelos nordestinos, sendo usado como ingrediente de pratos típicos da região e, durante a entressafra (fora da estação chuvosa), alcança preços altamente compensadores.

Sob condições de seca, a maioria dos agricultores nordestinos reluta em adubar os cultivos porque a falta e a má distribuição das chuvas, comuns no nordes- te, pode frustar completamente a safra. Contudo, com irrigação, os agricultores passaram a usar com maior freqüência os fertilizantes, especialmente os nitrogenados. A adubação do milho com nitrogênio é importante porque é um dos principais fatores responsáveis pelo aumento do rendimento dessa cultura, apesar de seus efeitos dependerem de fatores genotípicos (Melo et al., 1999) e ambientais (Wienhold et al., 1995).

Vários autores (Melgar et al., 1991; Novais et al., 1974) mostraram que o parcelamento da adubação nitrogenada pode proporcionar rendimento de grãos de milho superior ao obtido quando aplicado numa só vez. A comparação entre diferentes formas de parcelamento tem demonstrado ainda que os efeitos do parcelamento dependem das épocas em que o nitrogênio é aplicado (Esechie et al., 1995), bem como da quantidade des- te fertilizante que é aplicada em cada época (Bair et al., 1990). Outros autores (Reeves et al., 1993), entretanto, não têm encontrado vantagem em adubar parceladamente o milho, para melhorar o rendimento de grãos (Reeves et al., 1993; Sangoi \& Almeida, 1994).

O objetivo deste trabalho foi avaliar o efeito do parcelamento de $120 \mathrm{~kg}$ de $\mathrm{N}$ ha $^{-1}$ sobre a altura da planta e de inserção da espiga e sobre o rendimento de espigas verdes, avaliado pelo número e peso totais de espigas e pelo número e peso de espigas comercializáveis, empalhadas e despalhadas, da cultivar Centralmex.

\section{MATERIAL E MÉTODOS}

Dois experimentos semelhantes foram realizados na fazenda da ESAM, que dista aproximadamente $20 \mathrm{~km}$ da 
sede do município de Mossoró. O primeiro experimento foi realizado de julho a setembro de 1992 e o segundo, de agosto a novembro de 1993 . No período experimental de 1992, a temperatura média do ar variou de 27,0 a $27,9^{\circ} \mathrm{C}$, a umidade relativa do ar, de 59 a $78 \%$, a precipitação pluvial, de 0,4 a 9,6 mm e a insolação de 256 a 272 h. Em 1993, as variações respectivas foram de 28,3 a $29,2^{\circ} \mathrm{C}, 55$ a $57 \%, 0,0$ a $2,8 \mathrm{~mm}$ e 280 a $308 \mathrm{~h}$.

\section{Experimento de 1992}

A análise de uma amostra do solo da área experimental, um Argissolo Vermelho Amarelo (PVA) indicou: $\mathrm{pH}$, em água $=7,6 ; \mathrm{P}=51 \mathrm{mg} \mathrm{kg}^{-1}$ de solo; $\mathrm{K}^{+}=$ $0,42 \mathrm{cmol}_{\mathrm{c}} \mathrm{dm}^{-3} ; \mathrm{Ca}^{2+}=3,9 \mathrm{cmol}_{\mathrm{c}} \mathrm{dm}^{-3}$; $\mathrm{Mg}^{2+}=2,1 \mathrm{cmol} \mathrm{dm}^{-3} ; \mathrm{Al}^{3+}=0,0$ $\mathrm{cmol}_{c} \mathrm{dm}^{-3} \mathrm{e} \mathrm{Na}^{+}=0,27 \mathrm{cmol}_{c} \mathrm{dm}^{-3}$. O solo foi preparado a trator com duas gradagens e adubado manualmente, com $120 \mathrm{~kg}$ de $\mathrm{N}$ (sulfato de amônio), $60 \mathrm{~kg}$ de $\mathrm{P}_{2} \mathrm{O}_{5}$ (superfosfato simples), $30 \mathrm{~kg}$ de $\mathrm{K}_{2} \mathrm{O}$ (cloreto de potássio), por hectare. O fósforo e o potássio e todo ou parte do nitrogênio (de acordo com o parcelamento) foram aplicados como adubação de plantio em sulcos localizados $10 \mathrm{~cm}$ ao lado e abaixo dos sulcos de semeadura. Os tratamentos avaliados foram: aplicação de todo o nitrogênio por ocasião do plantio (1-0-0) ou em cobertura aos 25 (0-1-0) ou aos 45 (0-0-1) dias após o plantio e aplicação do fertilizante de forma parcelada (0-1/ $3-2 / 3,1 / 3-0-2 / 3,1 / 3-2 / 3-0,0-1 / 2-1 / 2,1 /$ $2-0-1 / 2,1 / 2-1 / 2-0,0-2 / 3-1 / 3,2 / 3-0-1 / 3$, 2/3-1/3-0 e 1/3-1/3-1/3). Nas adubações em cobertura (aos 25 ou 45 dias após o plantio) o nitrogênio foi colocado em filete contínuo, e deixado na superfície do solo, distante cerca de $10 \mathrm{~cm}$ das plantas, em cada fileira.

A área experimental foi irrigada por aspersão. A lâmina líquida requerida para o milho $(5,6 \mathrm{~mm})$ foi calculada considerando-se ser de $0,40 \mathrm{~m}$ a profundidade efetiva do sistema radicular. $\mathrm{O}$ momento de irrigar teve por base a água retida no solo à tensão de $0,04 \mathrm{MPa}$. O turno de rega foi de um dia e as irrigações foram iniciadas após o plantio e suspensas um dia antes de cada colheita.

Utilizou-se a variedade de polinização-livre Centralmex e o delineamento de blocos ao acaso com qua- tro repetições. As parcelas foram constituídas por três fileiras com $6,0 \mathrm{~m}$ de comprimento. Entre fileiras usou-se o espaçamento de $1,0 \mathrm{~m}$ x 0,4 m, com duas plantas por cova (densidade correspondente a 50 mil plantas ha-1). Como área útil, consideraram-se os 5,2 m centrais da fileira central de cada parcela. O plantio foi realizado em 7/7/1992.

O controle de invasoras foi feito com duas capinas realizadas com enxada aos 23 e 43 dias após o plantio e o controle de pragas (Spodoptera frugiperda Smith) foi feito com duas pulverizações de deltamethrin (300 $\left.\mathrm{ml} \mathrm{ha}^{-1}\right)$, realizadas aos sete e 24 dias após o plantio, usando-se pulverizador costal.

A colheita foi realizada parceladamente, de dois em dois dias (à medida que os grãos atingiam o "ponto de milho verde"), durante o período de 70 a 76 dias após o plantio. Por ocasião da colheita, foram avaliados os atributos: alturas da planta e de inserção da espiga (em dez plantas tomadas ao acaso na área útil de cada parcela), número e peso totais de espigas verdes empalhadas e número e peso de espigas comercializáveis, empalhadas e despalhadas. Como altura da planta, considerou-se a distância da superfície do solo ao ponto de inserção da lâmina foliar mais alta. Como altura de inserção da espiga, a distância da superfície do solo ao ponto de inserção da primeira espiga. Foram consideradas espigas empalhadas comercializáveis aquelas com tamanho superior a $23 \mathrm{~cm}$ e com aparência (ausência de manchas, de perfurações por pragas, etc.) adequada à comercialização. Foram classificadas como espigas despalhadas comercializáveis aquelas com tamanho superior a $18 \mathrm{~cm}$ e com granação e sanidade adequadas à comercialização. As alturas da planta e de inserção da espiga foram avaliadas em razão da associação destes parâmetros com o vigor da planta e com o acamamento. O milho verde é comercializado, na região, como totais de espigas produzidas e totais de espigas comercializáveis, empalhadas ou despalhadas. Por essa razão, foram utilizados os seis critérios para avaliação do rendimento de espigas verdes. As dimensões das espigas, utilizadas como critério de avaliação, foram estabelecidas com base no tamanho nas espigas comercializadas na região.

\section{Experimento de 1993}

Foi instalado de maneira semelhante ao anterior, com as seguintes modificações. A análise de amostra do solo da área experimental (em outro local, do mesmo solo) apresentou os seguintes resultados: $\mathrm{pH}$ em água $=7,5 ; \mathrm{P}=55$ mg P.kg-1 de solo; $\mathrm{K}^{+}=0,35 \mathrm{cmol}_{\mathrm{c}} \mathrm{dm}^{-3}$; $\mathrm{Ca}^{2+}=4,3 \mathrm{cmol}_{\mathrm{c}} \mathrm{dm}^{-3} ; \mathrm{Mg}^{2+}=2,1 \mathrm{cmol}_{\mathrm{c}}$ $\mathrm{dm}^{-3} ; \mathrm{Na}^{2+}=0,26 \mathrm{cmol}_{\mathrm{c}} \mathrm{dm}^{-3} ; \mathrm{Al}^{3+}=0,00$ $\mathrm{cmol} \mathrm{dm}^{-3}$. O plantio foi feito em 24/8/ 93. As capinas foram realizadas aos $31 \mathrm{e}$ 50 dias após o plantio e as pulverizações com inseticidas, aos 17 e 30 dias após o plantio.

A análise estatística dos dados experimentais foi feita através de uma análise conjunta, de acordo com o descrito por Gomes (1990). As médias foram comparadas a $5 \%$ de probabilidade, pelo teste de Tukey.

\section{RESULTADOS E DISCUSSÃO}

O parcelamento do nitrogênio não teve efeito sobre a altura da planta, mas as plantas em $1992(194 \mathrm{~cm})$ cresceram mais que em $1993(183 \mathrm{~cm})$. Na altura de inserção da espiga, somente as formas de parcelamento tiveram efeito significativo (Tabela 1). Nos dois anos de estudo, as médias da altura de inserção da espiga foram de 107 e $110 \mathrm{~cm}$, respectivamente. A maior altura de inserção da espiga foi obtida com a aplicação de $1 / 3$ do nitrogênio por ocasião do plantio e $2 / 3$ aos 25 dias após o plantio (1/3-2/3-0). Contudo, estatisticamente, este tratamento somente superou os de 0-0-1 e 1/3-0-2/3. A aplicação do nitrogênio por ocasião do plantio e 25 dias após parece ser importante na determinação da altura de inserção da espiga. Apesar dos efeitos dos tratamentos sobre a altura de inserção da espiga, não se verificou acamamento de plantas, nem foram alterados os procedimentos de colheita, feita na região manualmente. Esechie et al. (1995), ao contrário do observado neste trabalho, não constataram efeitos de diferentes formas de parcelamento na altura da planta, diâmetro basal do caule e número de folhas por planta.

No número total de espigas verdes 
Tabela 1. Médias, de dois anos e de quatro repetições, da altura de inserção da espiga, número e peso totais de espigas verdes empalhadas, número e peso de espigas comercializáveis, da cultivar de milho Centralmex, em razão do parcelamento de 120 kg N ha-1. Mossoró, ESAM, 1993.

\begin{tabular}{|c|c|c|c|c|c|c|c|c|c|}
\hline \multicolumn{3}{|c|}{$\begin{array}{c}\text { Dias da } \\
\text { semeadura }\end{array}$} & \multirow{3}{*}{$\begin{array}{l}\text { Altura de } \\
\text { inserção da } \\
\text { espiga } \\
\text { (cm) }\end{array}$} & \multirow{3}{*}{$\begin{array}{c}\text { No. total de } \\
\text { espigas } \\
\text { empalhadas } \\
\text { ha-1 }^{-1}\end{array}$} & \multirow{3}{*}{$\begin{array}{c}\text { Peso total } \\
\text { espigas } \\
\text { empalhadas } \\
\left(\mathrm{kg} \mathrm{ha}^{-1}\right)\end{array}$} & \multirow{3}{*}{$\begin{array}{c}\mathrm{N}^{0} \text { Espigas } \\
\text { empalhadas } \\
\text { comercial } \\
\text { ha }^{-1}\end{array}$} & \multirow{3}{*}{$\begin{array}{c}\text { Peso } \\
\text { espigas } \\
\text { empalhadas } \\
\text { comercial } \\
\left(\mathrm{kg} \mathrm{ha}^{-1}\right)\end{array}$} & \multirow{3}{*}{$\begin{array}{c}\text { No espigas } \\
\text { despalhadas } \\
\text { comercial } \\
\text { ha }^{-1}\end{array}$} & \multirow{3}{*}{$\begin{array}{c}\text { Peso } \\
\text { espigas } \\
\text { despalhadas } \\
\text { comercial } \\
\left(\mathbf{k g ~ h a}^{-1}\right)\end{array}$} \\
\hline 0 & 25 & 45 & & & & & & & \\
\hline \multicolumn{3}{|c|}{$\begin{array}{c}\text { Proporções de } \mathbf{N} \\
\text { aplicadas }\end{array}$} & & & & & & & \\
\hline 1 & 0 & 0 & $100 \mathrm{abc}$ & $40.951 \mathrm{c}$ & $5.962 \mathrm{e}$ & $12.415 \mathrm{e}$ & $2.875 \mathrm{e}$ & $10.889 \mathrm{~d}$ & $1.609 \mathrm{~d}$ \\
\hline 0 & 1 & 0 & $101 \mathrm{abc}$ & $47.178 \mathrm{abc}$ & $8.729 \mathrm{bcd}$ & 24.076 abcde & $5.884 \mathrm{abcd}$ & $17.733 \mathrm{abcd}$ & $2.655 \mathrm{abcd}$ \\
\hline 0 & 0 & 1 & $88 \mathrm{c}$ & 51.786 a & $10.890 \mathrm{a}$ & $32.278 a b$ & 8.132 a & 26.412 a & 4.152 a \\
\hline $1 / 2$ & $1 / 2$ & 0 & $111 a b$ & $41.185 \mathrm{c}$ & $7.030 \mathrm{de}$ & $17.942 \mathrm{de}$ & $4.254 \mathrm{de}$ & $11.496 \mathrm{~cd}$ & $1.686 \mathrm{~cd}$ \\
\hline $1 / 2$ & 0 & $1 / 2$ & $101 a b c$ & $50.022 a b$ & $9.474 a b c$ & $27.732 \mathrm{abcd}$ & $6.700 \mathrm{abcd}$ & $23.623 a b$ & $3.684 a b$ \\
\hline 0 & $1 / 2$ & $1 / 2$ & $105 a b c$ & $48.250 \mathrm{abc}$ & $10.327 \mathrm{ab}$ & $29.934 \mathrm{abc}$ & 7.762 a & $24.881 a b$ & 3.964 a \\
\hline $1 / 3$ & $2 / 3$ & 0 & 115 a & 43.625 bc & $7.659 \mathrm{cde}$ & 21.898 bcde & 4.802 bcde & $15.202 \mathrm{bcd}$ & $2.160 \mathrm{bcd}$ \\
\hline $1 / 3$ & 0 & $2 / 3$ & 94 bc & $48.172 \mathrm{abc}$ & $9.944 a b$ & $30.365 \mathrm{abc}$ & $7.446 \mathrm{abcd}$ & $24.863 a b$ & $3.787 a b$ \\
\hline 0 & $1 / 3$ & $2 / 3$ & $102 a b c$ & $48.366 \mathrm{abc}$ & 10.878 a & 33.281 a & 8.680 a & 27.665 a & $4.395 a$ \\
\hline $2 / 3$ & $1 / 3$ & 0 & $111 a b$ & 41.642 c & $6.822 \mathrm{de}$ & $19.711 \mathrm{cde}$ & $4.564 \mathrm{cde}$ & $14.558 \mathrm{bcd}$ & $2.034 \mathrm{bcd}$ \\
\hline $2 / 3$ & 0 & $1 / 3$ & $99 \mathrm{abc}$ & $48.170 \mathrm{abc}$ & $8.788 \mathrm{abcd}$ & 24.336 abcde & 5.809 abcde & $18.346 \mathrm{abcd}$ & $2.728 \mathrm{abcd}$ \\
\hline 0 & $2 / 3$ & $1 / 3$ & $110 a b$ & $47.367 \mathrm{abc}$ & $10.232 \mathrm{ab}$ & $29.102 a b c$ & $7.648 a b$ & $21.610 \mathrm{abc}$ & $3.161 \mathrm{abc}$ \\
\hline $1 / 3$ & $1 / 3$ & $1 / 3$ & $113 a b$ & $47.041 \mathrm{abc}$ & 8.684 bcd & 26.948 abcde & $5.959 \mathrm{abcd}$ & $19.514 \mathrm{abcd}$ & $2.866 \mathrm{abcd}$ \\
\hline \multicolumn{2}{|c|}{ C.V. (\%) } & & 11 & 10 & 14 & 25 & 28 & 31 & 35 \\
\hline
\end{tabular}

${ }^{1}$ Para cada característica, médias seguidas pela mesma letra não diferem entre si, a 5\% de probabilidade, pelo teste de Tukey.

empalhadas houve efeito significativo de parcelamento e ano (em 1992 foram produzidas 45.014 espigas e em 1993, 47.872 espigas), mas no peso destas espigas houve efeito somente de parcelamento. Em ambos, o maior rendimento foi obtido com a aplicação de todo o nitrogênio aos 45 dias após o plantio (tratamento 0-0-1) (Tabela 1). Entretanto este tratamento, para peso total de espigas, teve efeito comparável ao 0-1/ $3-2 / 3$. Observa-se que foi importante a aplicação de todo ou de $2 / 3$ do nitrogênio aos 45 dias após o plantio, para obtenção de maiores rendimentos totais de espigas verdes. Os menores números de espigas foram obtidos, em geral, nas parcelas em que nenhum nitrogênio foi aplicado aos 45 dias após o plantio. Igualmente, o menor peso total de espigas foi obtido nos tratamentos 1-0-0, 1/2-1/2-0, e 2/3-1/3-0. Deve-se destacar que, para as duas características, o menor número de espigas e o menor peso das mesmas foram obtidos quando todo o nitrogênio foi aplicado por ocasião do plantio.

No peso e número de espigas empalhadas comercializáveis, houve efeito significativo de anos e de parcelamento. Em 1992, foram produzidas 27.709 espigas que pesaram 6.653 $\mathrm{kg} \mathrm{ha}^{-1}$. Em 1993, as 23.063 espigas pesaram $5.733 \mathrm{~kg} \mathrm{ha}^{-1}$. Em ambas, o tratamento $0-1 / 3-2 / 3$ destacou-se como o melhor, porém não diferindo do 0-0-1, especialmente no que se refere ao peso das espigas (Tabela 1). Nestas duas variáveis, portanto, ocorreram efeitos semelhantes aos observados no número e peso totais de espigas. Isto é, os rendimentos tenderam a ser menores, quando parte da adubação nitrogenada não foi efetuada aos 45 dias depois do plantio.

A análise de variância também indicou efeito significativo de anos e de parcelamento no número e peso de espigas despalhadas comercializáveis. Em 1992 foram produzidas 24.288 espigas que pesaram $15.281 \mathrm{~kg} \mathrm{ha}^{-1}$ e em 1993 foram produzidas 15.218 espigas que pesaram $2.372 \mathrm{~kg} \mathrm{ha}^{-1}$. Os tratamentos 0-1/3-2/3 e 0-0-1 propiciaram os melhores rendimentos de espigas verdes despalhadas comercializáveis (Tabela 1). Quando este rendimento foi avaliado pelo peso de espigas verdes despalhadas comercializáveis, o tratamento 0-1/2-1/ 2 também mostrou-se vantajoso.

Os dados da Tabela 1 indicam que a aplicação da dose integral (0-0-1) pode ser equivalente a aplicações parceladas (0-1/ $3-2 / 3$ e, em alguns casos, 0-1/2-1/2) no que se refere à obtenção de maiores rendimentos de espigas verdes de milho.

A quantidade de nitrogênio no solo é afetada pelo ambiente e por práticas de manejo da cultura. Dentre os fatores que aumentam o teor de $\mathrm{N}$ no solo estão a dose aplicada, a mineralização do $\mathrm{N}$ da matéria orgânica do solo, deposição do $\mathrm{N}$ atmosférico e a fixação biológica do $\mathrm{N}_{2}$. Os fatores de perda são a absorção pelas plantas, lixiviação do nitrato, imobilização, desnitrificação e volatilização de $\mathrm{NH}_{3}$ (Buerkert et al., 1995).

A aplicação do nitrogênio, de uma só vez ou parceladamente, pode ser mais ou menos eficiente, dependendo da época em que o adubo é aplicado. Por exemplo, quando o nitrogênio foi aplicado totalmente aos 45 dias (0-0-1) propiciou rendimentos superiores às aplicações apenas no plantio (1-0-0) e aos 25 dias (0-1-0). Com o tratamento 0-1/2-1/2 foram obtidos maiores rendimentos que os conseguidos com os tratamentos 1/2-1/ $2-0$ e 1/2-0-1/2. Com outras formas de parcelamento, a tendência foi semelhante. Constata-se que quando o nitrogênio foi aplicado mais tardiamente, os rendimentos foram melhores. Quando a adubação nitrogenada é feita mais tardia, o $\mathrm{N}$ é fornecido à planta na época em que sua absorção é máxima, o que 
ocorre duas a três semanas antes da floração (Russelle et al., 1983), apesar da absorção do N pelo milho continuar até próximo à maturidade (Andrade, 1975). A cultivar Centralmex utilizada no presente trabalho floresce, na região, em torno de 60 a 65 dias após o plantio, isto é, aproximadamente três semanas após a última aplicação (45 dias após o plantio). Andrade (1975), avaliando a extração e exportação de macro e micronutrientes por cinco cultivares de milho, dentre as quais a cultivar Centralmex, usada neste trabalho, verificou que o $\mathrm{N}$ foi acumulado na parte aérea da planta até os 80 dias após a germinação, decrescendo depois disto em razão de degenerescência e perda de partes vegetativas e de excreção pelo sistema radicular. Deve ser dito ainda que a aplicação tardia limita ou reduz o potencial para perda do $\mathrm{N}$ por lixiviação ou desnitrificação, pois, o N permanece no solo por um período de tempo menor e porque por essa ocasião já existe um sistema radicular ativo em crescimento, para absorção do nitrogênio aplicado (Olson \& Kurtz, 1982). Mackay \& Barber (1986) atribuíram parcialmente a melhor resposta ao nitrogênio do híbrido B73 x MO17, em termos de rendimento de grãos, a uma maior extensão do sistema radicular deste híbrido. Nos experimentos nos quais se baseou este trabalho, realizados com irrigação, a água deve ter contribuído para perdas do nutriente, especialmente quando ele foi aplicado em grandes proporções por ocasião do plantio. Bigeriego et al. (1979) verificaram que a maior utilização do N na produção de grãos, com aplicações tardias desse fertilizante, foi devida a absorção e translocação mais ativas durante o período de enchimento dos grãos. O solo experimental, muito arenoso, mas de ocorrência generalizada na região em que foi realizado o experimento, é outro fato que pode ter contribuído para as perdas do referido fertilizante. Deve ser mencionado que Reichardt et al. (1982) concluíram que perdas por lixiviação não constituem problema, com aplicações da ordem de $90 \mathrm{~kg}$ de $\mathrm{N} \mathrm{ha}^{-1}$. Na verdade, segundo Yamada \& Abdalla (2000), as principais perdas de $\mathrm{N}$ ocorrem na forma de gases, que são liberados na atmosfera, ocasionadas por volatilização da amônia e por desnitrificação, realizada por bactérias encontradas no solo, e por imobilização biológica. Segundo eles, as perdas por volatilização seriam evitadas pela incorporação da uréia em profundidade, misturando-se uréia e cloreto de potássio na forma líquida ou misturando-se uréia e sulfato de amônio. Neste trabalho, os valores do $\mathrm{pH}$ do solo $(7,6$ e 7,5) podem ter contribuído para as perdas por volatilização. É bem conhecido que fertilizantes nitrogenados, mesmo na forma amoniacal, quando aplicados em solos com pH alcalino, são perdidos por volatilização, na forma de amônia $\left(\mathrm{NH}_{3}\right)$, em quantidades que podem ser significativas.

Resultados semelhantes aos aqui relatados, para rendimento de espigas verdes, foram observados por Novais et al. (1974) para peso de espigas maduras de milho. Segundo eles, a aplicação parcelada do adubo nitrogenado (1/3 no plantio e $2 / 3$ aos 45 dias) e de todo o adubo aos 45 dias depois do plantio foram os melhores tratamentos para a produção de espigas. Esechie et al. (1995) verificaram que o parcelamento $1 / 3-2 / 3-0$ (plantio-42 dias-63 dias) foi superior aos parcelamentos 1/3-0-2/3 e 1/3-1/3-1/3, para rendimento de grãos.

Também como foi constatado neste trabalho para rendimento de espigas verdes, Melgar et al. (1991) verificaram que o menor rendimento de grãos foi obtido quando o nitrogênio foi aplicado de uma só vez, em doses que variaram de 40 a $120 \mathrm{~kg}$ de $\mathrm{N} \mathrm{ha}^{-1}$, por ocasião do plantio.

Pode-se concluir portanto, que os efeitos dos tratamentos foram independentes dos efeitos de anos. Os tratamentos (0-0-1) e (0-1/3-2/3) foram os que, em geral, proporcionaram os maiores rendimentos, mas outros tratamentos propiciaram rendimentos comparáveis. Os piores rendimentos foram obtidos com o tratamento 1-0-0.

\section{LITERATURA CITADA}

ANDRADE, A.G. Acumulação diferencial de nutrientes por cinco cultivares de milho (Zea mays L.). Piracicaba, ESALQ/USP, 1975. 75 p. (Tese mestrado).

BAIR, W.; McGAHEN, J.H.; AYERS, J.E. Effect of time and rate of $\mathrm{N}$ side dress application on Northern corn leaf blight severity and the associated yield loss. Journal of Production Agriculture, v. 3,n. 1, p. 44-49, 1990.
BIGERIEGO, M.; HAUCK, R.D.; OLSON, R.A. Uptake, translocation and utilization of ${ }^{15} \mathrm{~N}$ depleted fertilizer in irrigated corn. Soil Science Society American Journal, v.43, n.3, p. 528-533, 1979.

BUERKERT, B.; HORLACHER, D.; MARSCHNER, H. Time course of nitrogen in soil solution and nitrogen uptake in maize plants as affected by form and application time of fertilizer nitrogen. Journal of Agronomy \& Crop Science, v. 174 , n. 2, p. 325-336, 1995.

ESECHIE, H.A.; ELIAS, S.; MAGPANTAY, J. Timing of nitrogen application to enhance corn (Zea mays L.) yields in a desert climate. Journal of Agronomy \& Crop Science, v. 175, n. 4, p. 271$278,1995$.

GOMES, F.P. Estatística experimental. 13. ed. Piracicaba: Nobel, 1990. 232 p.

MACKAY, A.D.; BARBER, S.A. Effect of nitrogen on root growth of two corn genotypes in the field. Agronomy Journal, v. 78, n. 4, p. 699703, 1986.

MELGAR, R.J.; SMYTH, T.J.; CRAVO, M.S. Aplicação de fertilizante nitrogenado para milho em Latossolo da Amazônia. Revista Brasileira de Ciência do Solo, Campinas, v. 15, n. 2, p. 289296, 1991.

MELO, W.M.C.; PINHO, R.G.V.; PINHO, E.V.R.V.; CARVALHO, M.L.M.; FONSECA, A.. Parcelamento da adubação nitrogenada sobre o desempenho de cultivares de milho para produção de forragem. Ciência e Agrotecnologia, Lavras, v. 23, n. 3, p. 608-616, 1999.

NOVAIS, M.V.; NOVAIS, R.F.; BRAGA, J.M. Efeito da adubação nitrogenada e de seu parcelamento sobre a cultura do milho, em Patos de Minas. Revista Ceres, Viçosa, v. 21, n. 115, p. 193-202, 1974.

OLSON, R.A.; KURTZ, L.T. Crop nitrogen requirements, utilization and fertilization. In: STEVENSON, F.J. Nitrogen in agricultural soils. Madison: American Society of Agronomy, 1982. 960 p., p. 567-604.(ASA Monograph, v. 22)

REEVES, D.W.; WOOD, C.W.; TOUCHTON, J.T. Timing of nitrogen applications for corn in a winter legume conservation-tillage system. Agronomy Journal, v. 85, n. 1, p. 98-106, 1993. REICHARDT, K.; LIBARDI, P.L.; URQUIAGA, S.C. Fate of fertilizer nitrogen in soil-plant systems with emphasis on the tropics. In: INTERNATIONAL ATOMIC ENERGY AGENCY. Agrochemicals: fate in food and the environment. 1982.380 p. p. 277-290.

RUSSELLE, M.P.; HAUCK, R.D.; OLSON, R.A. Nitrogen accumulation rates of irrigated maize. Agronomy Journal, v. 75, n. 5, p. 593-598, 1983. SANGOI, L.; ALMEIDA, M.L. Doses e épocas de aplicação de nitrogênio para a cultura do milho num solo com alto teor de matéria orgânica. Pesquisa Agropecuária Brasileira, Brasília, v. 29, n. 1, p. 13-24, 1994.

WIENHOLD, B.J.; TROOIEN, T.P.; REICHMAN, G.A. Yield and nitrogen use efficiency of irrigated corn in the Northern Great Plains. Agronomy Journal, Madison, v. 87, n. 5, p. 842-846, 1995.

YAMADA, T.; ABDALLA, S.R.S. Como melhorar a eficiência da adubação nitrogenada do milho?. Piracicaba: POTAFOS, 2000. (Informações Agronômicas, n. 91), p. 1-5. 